\title{
TOPSIS ve VIKOR Yöntemleri Kullanılarak OECD Ülkelerinin Sağlık Kaynağı Göstergeleri Açısından Karşılaştırılması
}

DOI: $10.26466 /$ opus. 961183

\author{
Yeter Demir Uslu* \\ * Prof. Dr., İstanbul Medipol Üniversitesi, Sağlık Bilimleri Fakültesi, İstanbul/Türkiye \\ E-Posta: yuslu@medipol.edu.tr \\ ORCID: $\underline{0000-0002-8529-6466}$
}

\begin{abstract}
Öz
Bu çalışmada sekiz farklı sağlık kaynağı göstergesinin çok kriterli karar verme yöntemleri kullanılarak OECD ülkelerinin karşılaştırılmasının yapılması amaçlanmıştır. 2019 yılı verileri kullanılan çalışmada eksik verileri bulunan ülkeler velveya göstergeler çalışmaya dahil edilmemiştir. Çok kriterli karar verme yöntemlerinden TOPSIS ve VIKOR yöntemleri kullanılarak, belirlenen sağllk kaynağı göstergeleri açısından ülkelerin sıralamaları yapılmış ve nihayetinde iki yöntem ile elde edilen sonuçların karşılaştırllması yapılmıştır. Çalışma kapsamında ele alınan kriterlerin eş derecede öneme sahip oldukları varsayılmış ve TOPSIS ile VIKOR analizleri bu varsayım altında yapılmıştır. Yöntemlerin uygulanmasında Microsoft Excel programı kullanılmıştır. Çalışmada kullanılan kriterlerden beş tanesi, OECD'nin yapmış olduğu sağlık kaynakları sinfflandırmasında yer alan "medikal teknoloji" göstergelerine aittir. OECD ülkelerinin sıralanması amacıyla, literatürdeki diğer çalı̧̧malardan farklı olarak medikal teknoloji göstergelerinin de değerlendirilmesi çalışmanın özgün yanın oluşturmaktadır. TOPSIS ve VIKOR yöntemleri ile yapilan analizler sonucunda benzer stralamalar elde edilmiştir. Türkiye'nin, çalışmada ele alınan 26 OECD ülkesi arasında her iki yöntemde de 25. sırada yer aldığ̆ görülmüştür. Gelişmiş ve zengin ülke sağllk kaynağı seviyelerine erişebilmek için Türkiye'nin ilave kaynaklara ihtiyacı olduğu ve mevcut kaynakların daha fazla medikal teknoloji alanına yönlendirilmesi gerekliliği sonucuna varılmıştir.
\end{abstract}

Anahtar Kelimeler: TOPSIS, VIKOR, Sağllk Kaynakları, Sağllk Kaynağg Göstergeleri, OECD Ülkeleri. 


\title{
Comparison of OECD Countries in Terms of Health Resource Indicators Using TOPSIS and VIKOR Methods
}

\begin{abstract}
This study, it is aimed to compare the OECD countries by using multi-criteria decision-making methods of eight different health resource indicators. Countries andlor indicators with missing data were not included in the study, in which 2019 data were used. TOPSIS and VIKOR methods, which are among the multi-criteria decision-making methods, were used and the countries were ranked in terms of the determined health resource indicators and finally, the results obtained by the two methods were compared. It was assumed that the criteria covered in the study were of equal importance and TOPSIS and VIKOR analyzes were performed under this assumption. Microsoft Excel program was used in the implementation of the methods. Five of the criteria used in the study belong to the "medical technology" indicators in the OECD's health resources classification. To rank OECD countries, the evaluation of medical technology indicators, unlike other studies in the literature, is the original aspect of the study. Similar rankings were obtained as a result of analyzes with TOPSIS and VIKOR methods. It has been observed that Turkey ranks 25th in both methods among the 26 OECD countries covered in the study. It has been concluded that to reach the health resource levels of developed and rich countries, Turkey needs additional resources and that existing resources should be directed to more medical technology areas.
\end{abstract}

Keywords: $\quad$ TOPSIS, VIKOR, Health Resources, Health Resource Indicators, OECD Countries. 


\section{Giriş}

“Lustig'e göre sağlık, sadece hastalığın olmaması değil aynı zamanda bireylerin tüm yaşamı boyunca kendi potansiyelini geliştirme kapasitesini ifade etmektedir (Lustig, 2007, s.1; Hayaloğlu ve Bal, 2015). Sağlıklı olmak bir refah kaynağı ve dünya çapında insanlığın en değerli amaçlarından biridir. Aynı zamanda Barro (1996)'na göre sağlık, ekonominin motoru ve sermaye üreten bir varlıktır (Ecevit ve Çetin, 2010).

Sağlık hizmetleri bir ülkede sosyo-ekonomik faktörler doğrultusunda refah düzeyinin başlıca ölçütlerinden biri olarak karşımıza çıkmaktadır. Hasta beklentisi ile doğru orantılı olarak en düşük maliyetle ve yüksek kalite düzeyinde hizmet sunmak, bu hizmeti gerektiği her an da hasta ile buluşturabilmek; sağlık hizmetlerinin temel amaçları arasındadır. Yaşanan teknolojik gelişmeler ile birlikte, artan maliyetler, hastaların artan şikâyetleri ve kaliteli sağlık hizmetine olan isteğin artması sağlık hizmetlerinin daha komplike bir yapıya evrilmesine sebebiyet vermiştir. Nitekim sistem içerisinde faaliyet gösteren yapılar azalan bütçelerle yenilikçi ve gelişmiş teknolojilere sahip ürünlerle hizmet sunma konusunda baskı altındadırlar. Teknoloji de yaşanan gelişmeler mutlaka bir maliyet doğurur. Nitelikli sağlık insan gücüne ihtiyacın önemi aşikâr olmakla birlikte, hizmet sunumunda kullanılacak sarf malzeme tedarik ve stok durumlarının da sürdürülebilir nitelikte olması; ülkenin refah düzeyi, ekonomik gücü, ödeme kapasitesi ve sağlık hizmetlerine ayrılan pay ile doğrudan orantılidir.

Sağlık hizmetlerinin kalite düzeyini yükseltmek için doğru kişiye doğru zamanda ve doğru sonuçlar yaratacak şekilde ulaştırılması ve sağlık sisteminin daha etkin işletilebilmesi için her geçen gün sistemin değişen koşullar nezdinde duyarlılığı sorgulanmalıdır. Değişen şartlar doğrultusunda dünya genelinde tüm ülkelerin kendi vatandaşlarının sağlık düzeylerini artırmak, sağlığı korumak ve geliştirmek, tedavi süreçlerinin etkililiğini artırmak ve bunlarla birlikte sağlık harcamalarından doğan maliyetleri minimize ederek kontrol altına almak gibi çeşitli hedefleri vardır ve bu hedefler nihayetinde farklı sağlık sistemleri gelişmiştir. Sağlık sistemlerinin geneli sağlık hizmet sunumu için kaynakları belirler ve sürecin yönetimini, organizasyonunu ve kaynak tahsisini sağlamakla yükümlüdürler (Culyer ve Newhouse, 2000, s.13). 
Kaynak yönetimi, yönetim olgusunun bütçe ve planlama dahil olmak üzere tüm işlevlerinin analitik ya da stratejik esası olarak görülebilir (Acar, 2015, s.518-23; Arıkboğa, 2015, s.146-7; Avaner ve Avaner, 2018). Nitekim kurumsal amaçlara ulaşmada gerekli olan tüm kaynakların etkin bir şekilde kullanılmasını sağlar. Kaynak yönetimi kurumsal hedefler ve kurumsal kapasiteye ilişkin kapsamlı bir anlayış ve şeffaflık gerektirir. Bu bağlamda etkin bir kaynak yönetimi, öngörülemeyen aksaklıkların önlenmesi noktasında önem taşır. Öyle ki, söz konusu proaktif bakış açısı hız ekonomisinin de gereğidir. Yine olası bir başarısızlık durumunda yönetsel süreç içerisinde gerçekleştirilen planlama faaliyetleriyle yapılan işlerin safahatı hakkında da kolaylıkla bilgi alınabilir. Son olarak da verimliğin ölçülmesinde kullanılabilir.

Sağlık kurumları açısından bir kaynak yönetimi planına sahip olmak, insan kaynağını, malzemeleri ve bütçe verimliliğini optimize etmek için etkili bir araçtır. Kurumsal süreçlerde yetersiz ya da verimsiz kullanılan kaynakların keşfinin yapılması ve amacına uygun olarak iş süreçlerine dahil edilmesi sağlıkta kalite anlayışına da hizmet etmektedir. Etkisiz ve yetersiz kaynak yönetimi anlayışı düşük üretkenlik, düşük kalite, artan maliyetler, kaçırılan fırsatlar, düşük motivasyon vb. olumsuzlukları da beraberinde getirmektedir.

\section{Kaynak Kullanımı ile Sağlık Hizmet Çıktıları Arasındaki İlişki}

Kamu sağlık hizmetlerinin yönetilebilirliğini sağlamak için tüketim, tedarik ve teknoloji yönetimi süreçlerini de gerçekleştirmek ve aralarındaki organizasyonu yönetmek gerekmektedir. Bu organizasyon yönetimi; aralarındaki ilişkinin sürdürülebilirliğini sağlamak için karar verme süreçlerini de içermektedir.

"Kaynakların daha etkin kullanılması için sağlık hizmet sunucularına ilişkin yapılması gereken temel sistematik değişimler nelerdir?" sorusu kaynak kullanımının hizmetin çıtısına olan etkisini belirlemede kritik rol oynar.

DSÖ’ye göre; sağlık sistemlerinin herkes için sağlık hizmetlerinin ulaşılabilir kılınması ve en üst düzeyde kalite anlayışı ile kurgulanması gerekmektedir (Türkiye Sağlık Turizmi Derneği, 2021). Sunulan sağlık hizmetinin ise toplum genelinde kabul görmüş olması, etkili ve verimli bir 
sistematik içerisinde çalışması gerekir. Dünya genelindeki ülkeler ise bahsi geçen bu kriterler doğrultusunda kendine özgü sağllk sistemlerinin kurar ve geliştirirler.

Sağlıkta kaynak yönetimi, sağlık sisteminde yer alan kaynakların etkili ve verimli kullanılmasını sağlamak ve sağlık hizmet kalitesini arttırmak için sağlık tesislerinde stratejik planlama, finans yönetimi, bütçeleme, yönetim muhasebesi, müşteri ilişkileri yönetimi, insan kaynakları yönetimi ile denetim çalışmalarını da etkinleştirmek ve geliştirmek amacıyla kurgulanan bir süreçtir.

Türkiye' de sağlık hizmet sunumunda gerçekleştirilen harcamalara bakıldığında kamu hastaneleri üzerindeki maliyetlerin ne denli büyük olduğu ve kaynakların yönetiminin ne denli önemli olduğu gözler önüne serilmektedir. Ülkemizde sağlıkta kaynak denildiğinde ilk akla gelenler, insan kaynağı ve mali kaynaklar olmaktadır. Sağlık kuruluşlarında kuşkusuz insan kaynağ 1 yönetimi ile birlikte mali kaynakların yönetimi temel unsurlar arasında yer alır. Ancak insan kaynağ 1 ve mali kaynaklara ek olarak, hizmet sunumunda kullanılan malzemeler ve bununla ilişkili olarak etkin bir malzeme yönetimi ile birlikte bilgi ve iletişim teknolojileri alt yapısı temelinde (ICT) sağlık kaynaklarının da bu noktada temel bileşenler olduğu unutulmamalıdır. Nitekim bu bakış açısı hizmetin sürdürülebilirliğini sağlamak ve hizmet kalitesini hedeflenen düzeye ulaştırabilmek için hayati değer taşır. Donabedian'a göre sağlık hizmetlerinde kalite; “teknik kişiler ve çevresel etkenlerin bir ürünü" olarak tanımlanmaktadır (Gulhan ve Coskun, 2017). Özetle, ulusal ve uluslararası literatür genel olarak değerlendirildiğinde sağlığın kaynakları sınıflandırılması;

1. Çalışanlar (Tıp, hemşirelik, klinik ve yönetsel destek)

2. Malzemeler (Tibbi ve diğer)

3. Bina Ekipmanları (Bilgi ve İletişim Teknolojileri)

4. Parasal Kaynaklar, şeklinde yapılabilir.

Sağlık süreçlerinin yeniden tasarımı elzem bir konu olarak karşımıza çıkmaktadır. Sağlık hizmet sunumundaki kalite eksiklikleri, güven problemleri, sağlık harcamalarının artışı, süreç içerisindeki gereksiz işlemler ve faaliyetler, önlenebilir hataların artması gibi durumlar yeni bir süreç tasarımını gerekli kılmaktadır (Yüksel, 2012). 
Sağlık hizmetinin en temel özelliklerinden birisi emek yoğun olmas1dır. Aynı zamanda hizmetin üretilmesi için karşılıklı bağımlılık ve iş bölümü diğer sektörlere nazaran daha fazladır. Sağlık hizmet sunucuları verdikleri hizmetin çeşitliliği, büyüklüğü gibi faktörleri göz önüne alarak yeterli insan gücü istihdam etmek durumundadır.

Sağlık hizmet sunumunda kaliteden ödün vermeden hakkaniyetli, etkili ve verimli bir sürecin yürütülebilmesi nitelikli sağlık insan gücü ile doğrudan orantılıdır. Güncel ve kanıta dayalı bilgiler ışığında eğitim almış, takım çalışmasına yatkın, analitik düşünme becerisine sahip ve iyi iletişim kurmayı kendine tutum edinmiş bireylerden nitelikli sağlık ordusu oluşturulmalıdır. Sağlık insan gücü planlaması tüm ülke genelinde dengeli olarak yapılmalıdır.

Sağlık hizmetlerinde kullanılan malzemelerin yönetimi; malzemenin planlanması, koordinasyonu ve kontrolünden sorumlu bir akış sürecidir. Malzeme yönetimini daha iyi anlayabilmek için planlama, tedarik, lojistik, taşıma, stok kontrolü ve atık kontrolü süreçlerini iyi irdelemek gerekir.

Tedarik faaliyetleri sonrası sarf malzemenin uygun koşullarda depolanması, dağıtım kanallarının belirlenerek hızlı ve zamanında teslimatın gerçekleşmesi ve kullanımının sağlanması gerekmektedir. Bu doğrultuda işletme içerisinde depo birimlerinin oluşturulması ve yönetilmesi de tedarik faaliyetleri arasında değerlendirilmelidir (Bekmezci, 2018). İyi düşünülerek planlanmış bir tedarik zinciri sistemi hem stok değerleme süreçlerindeki hatayı azaltır hem de sarf malzemenin dağıtım kanallarına düzenli ve sistematik olarak dağıtımını sağlayarak hizmet sunum sürecinin kalitesini artırır (Tutuncu ve Kucukusta, 2008, s.31). Kamu ve özel sağlık işletmeleri, hastalar, üreticiler, tedarikçiler, eczane, tıbbi cihaz firmaları, sosyal güvenlik kurumu, özel sigorta şirketleri, aile hekimliği merkezleri gibi sağlık hizmeti ile direkt veya dolaylı olarak ilişkili olan birimler sağlık sektörünün tedarik zinciri aktörlerini oluşturmaktadır. Sağlık hizmet sektörü için üreticiler kavramının içeriği; ilaç, tıbbi cihaz, cerrahi araç, sarf malzeme, protez, medikal cihaz ve ekipman, hastane bilgi yönetim sistemleri üreticileri şeklinde tanımlanabilir (Burns vd., 2002, s.12; Özcan, 2013, s.285-286; Tengilimoğlu ve Yiğit, 2013, s.28-39).

Sağlık hizmeti sunumunda kullanılan binalarının inşaatından itibaren tüm tasarım ve süreçlerde modern teknolojilerin kullanımının yaygınlaşmasına, klinik ve klinik dışı tüm iş akışların düzenlenmesine, süreç odaklı 
ve ergonomik olmasına özen gösterilmektedir. Kuruluş için doğru kaynak yönetimi araçlarını kullanmak hizmetin çıtısını önemli ölçüde etkiler. Sağlık hizmeti sunucularının nitelikli hizmet vermesini sağlamak, iş yükünü azaltmak, güvenli kayıt tutmalarını sağlamak, kişisel ve mesleki gelişimlerini artırmak amacı ile bilgi ve iletişim teknolojisinin kullanımı dolayısıyla sağlık bilişimi büyük önem taşımaktadır. Bilgi iletişim süreçleri, etkili ve verimli kaynak yönetimi süreçlerinin başarısında kilit rol oynar. Bilgi yönetim sistemleri, bu veri, bilgi ve belgelerin oluşturulması, işlenmesi, biçimlendirilmesi, analiz edilmesi ve anlamlandırılması, kullanılması, paylaşılmasını içeren uygulamalardır. Dünya çapında ve Türkiye'de yaşanan dijital dönüşümün etkileri sonucunda sağlık bilgi sistemlerinin oluşturulması elzem bir konu olarak ortaya çıkmıştır. Örneğin, Sağlıkta Dönüşüm Programı (SDP) çerçevesinde oluşturulan Ulusal Sağlık Bilgi Sistemleri kapsamında ve Sağlık.Net çatısı altında Aile Hekimliği Bilgi Sistemi (AHBS), Çekirdek Kaynak Yönetim Sistemi (ÇKYS), Hastane Bilgi Yönetim Sistemleri (HBYS), Temel Sağlık İstatistikleri Modülü (TSIM) gibi alt uygulamalar bulunmaktadır.

Sağlik sektöründe yaşanan teknolojik gelişmeler ve dijital dönüşüm sayesinde hastaneler de daha teknolojik donanıma sahip olarak birer kağıtsız hastaneye evrilmişlerdir. Bu durum sağlık hizmet süreçlerini daha hızlı ve etkili olarak yönetebilme, öncelikli ve özellikli bakım gerektiren hastalara hizmeti daha hızlı ulaştırabilme potansiyelini artırmaktadır. Dijital hastane, her türlü tıbbi cihazın bilgi yönetim sistemine ağlar ve sensörler aracılığıyla veri/bilgi gönderebildiği; çalışanların ve hastaların yetki ve onamları dâhilinde bu sistemdeki veri/bilgiye hastaneden veya uzaktan erişebildiği entegre sağlık hizmeti sunan bir hastane modelidir.

2003 yılından itibaren Türkiye'de başlatılan Sağlıkta Dönüşüm programıyla birlikte sağlık sistemi dönüşüme giderek yeniden tasarlanmış ve sağlık reformları gerçekleştirilmiştir. Bu süreçte Genel Sağlık Sigortası kurularak ülke vatandaşlarının tamamını kapsamayı hedefleyen çatı bir kuruluş oluşturulmuştur. Bu doğrultu da ülke vatandaşlarının sağlık hizmeti kurum ve kuruluşlarına ulaşılabilirliği kolay kılınmış ve katastrofik sağlık harcamaları karşısında mali korumaları artırılmıştır. Gelişmekte olan ülkelere ve Türkiye'ye bakıldığında; sağlık indikatörleri ve sağlık harcama bütçeleri incelendiğinde gözler görülür bir oranda ortalamanın 
üzerinde başarı gösterdiği bilinmektedir. Nitekim bu durum OECD ülkeleri ile kıyaslandığında henüz sağlık indikatörlerinin yeterli seviyeye ulaşmadığ 1 tespit edilmiştir.

Türkiye nüfusuna bakıldığında son yıllarda yaşlı nüfusun artması ile birlikte gelecekte kronik hastalık yükünün artacağı ve buna bağlı olarak sağlık harcamalarına ayrılan payın da yükseleceği öngörülmektir. Gelişmiş ülkelere bakıldığında da yaşlanan nüfus her geçen gün giderek artmaktadır. DSÖ'ye göre dünya doğuşta beklenen yaşam süresi ortalaması 1990 yılında 64 yıl iken, bu oran 2007'de 68 yıla çıkmıştır. 2050 yılında ise 76 yılı geçeceği öngörülmektedir. OECD ülkelerinde ise bu oran daha da yüksek seviyede olup 2005 yılında 78,6'ya 2010 da ise 79,8 yıl seviyelerine çıkmıştır. AB ülkelerinde ise 60 yaş ve üzeri nüfusun toplam nüfusa oranı 1950 yılında yüzde 12 iken, bu oran 2000 yılında yüzde 20'ye çıkmıştır (T.C. Kalkınma Bakanlığı, 2014). Özellikle bulaşıcı hastalıklarla ilgili yapılan tedavi ve koruma önlemleri, yaşlı sağlığını artırıcı hizmet süreçlerinin tasarlanması ile birlikte hastalık yükü içerisinde bulaşıcı olmayan hastalıkların oranı her geçen gün giderek artmaya devam etmektedir.

Hastalık yüklerinin değişmesi, yaşlı nüfusun artması, kalış sürelerinin uzaması, sağlık teknolojilerinde yaşanan değişiklikler gibi faktörler göz önüne alındığında sağlık sisteminin organizasyonu, yönetimi ve finansman yöntemlerinde yeniden yapılacak süreç tasarımlarına olan ihtiyacı gözler önüne sermektedir. Türkiye' de yapılan öngörü çalışmalarına göre 2025 yılı itibarıyla her on vatandaştan birisi 65 yaş ve üzeri nüfus içerisinde yer alacaktır (Türkiye İstatistik Kurumu, 2012). Buna bağlı olarak toplam nüfus artışları da göz önüne alındığında sağlık ve sosyal güvenlik sisteminin mali harcamalarını artıracağ 1 ve finansman kaynakları üzerinde büyük bir yük getireceği aşikardır.

\section{Sağlık Kaynakları}

OECD istatistiklerine göre, sağlık kaynakları (1)Toplam sağlık ve sosyal istihdam, (2)Doktorlar, (3)Ebeler, (4)Hemşireler, (5)Bakım personeli, (6)Diş hekimi, (7)Eczacılar, (8)Fizyoterapistler, (9)Hastane istihdamı, (10)Mezunlar, (11)Sağlık çalışanlarının maaşları, (12)Hastaneler, (13)Has- 
tane yatakları ve (14)Medikal teknoloji başlıkları altında değerlendirilmektedir. Başlıkların tek tek değerlendirilmesi ile toplam 124 adet sağlık kaynağı göstergesi OECD tarafından belirlenmiştir (OECD, 2021).

Çalışma kapsamında ele alınan kriterlerden beş tanesi ("bir milyon kişi başına düşen bilgisayarlı tomografi tarayıcı sayısı", "bir milyon kişi başına düşen manyetik rezonans görüntüleme birimi sayısı", "bir milyon kişi başına düşen pozitron emisyon tomografisi (PET) tarayıcı sayısı", "bir milyon kişi başına düşen mamograf sayısı" ve "bir milyon kişi başına düşen radyasyon tedavi ekipmanı sayısı") medikal teknoloji sınıfında değerlendirilen sağlık kaynaklarını kapsamaktadır.

Çalışmada kullanılan diğer değişkenler ise, ("1000 kişi başına düşen pratisyen hekim sayısı", "1000 kişi başına düşen uzman hekim sayısı" ve "1000 kişi başına düşen toplam hastane sayısı") OECD sınıflandırmasında doktorlar ve hastane yatakları sınıflarında değerlendirilmektedirler.

Eksik verileri bulunan OECD ülkeleri ve sağlık kaynağ 1 göstergeleri çalışmaya dahil edilmemiştir. Bu sebeple bu çalışmada 26 adet OECD ülkesinin belirlenmiş olan 8 adet sağlık kaynağı göstergesine göre sıralamaları yapılmıştır. Geçmişte yapılmış olan ülke karşılaştırmalarına dayanan çalışmalardan farklı olarak, sağlık kaynakları arasında önemli bir yeri bulunan medikal teknoloji göstergelerine bu çalışmada yer verilmiştir.

\section{Yöntem}

Çalışmanın yöntemi literatürde daha önceden çok kriterli karar verme yöntemlerinden TOPSIS ve VIKOR kullanılan bazı çalışmalar referans alınarak tasarlanmıştır (Yılmaz ve Yakut, 2021). Bu çerçevede çalışmada çok kriterli karar verme yöntemlerinden TOPSIS ve VIKOR yöntemleri kullanılarak, belirlenen sağlık kaynağı göstergeleri açısından ülkelerin sıralamaları yapılmış ve nihayetinde iki yöntem ile elde edilen sonuçların karşılaştırılması yapılmıştır. Çalışma kapsamında ele alınan kriterlerin eş derecede öneme sahip oldukları varsayılmış ve TOPSIS ile VIKOR analizleri bu varsayım altında yapılmıştır.

Çok kriterli karar verme yöntemlerinden biri olan TOPSIS yöntemi ile belirlenen kriterler göz önünde bulundurularak, karar alternatifleri arasından en iyi seçimin yapılmasına ve bu alternatiflerin sıralamasına imkan tanımaktadır (Özüdoğru ve Görener, 2018). TOPSIS (Technique for Order 
Preference by Similarity to Ideal Solution) 1981 yılında Hwang ve Yoon tarafından geliştirilmiştir.

TOPSIS yöntemi ile sıralama yapılırken, ilk sıralarda yer alabilecek olan alternatiflerin ideal çözüme yakın olması beklenirken, ideal olmayan (negatif ideal) çözüme uzak olması beklenmektedir. Farklı bir ifade ile, TOPSIS yönteminde alternatifler arasından ideal çözüme en yakın ve aynı zamanda negatif ideal çözüme en uzak olanın seçilmesi hedeflenmektedir. Yöntemin uygulanma aşamaları 6 adımdan oluşmaktadır (Özdemir, 2015):

1.Adım: Karar matrisinin oluşturulması

2.Adım: Normalize matrisin elde edilmesi

3.Adım: Ağırlıklandırılmış normalize matrisin elde edilmesi

4.Adım: İdeal ve negatif ideal çözüm değerlerinin elde edilmesi

5.Adım: İdeal ve negatif ideal noktalara olan uzaklık değerlerinin elde edilmesi

6.Adım: İdeal çözüme göreli yakınlığın hesaplanması

Çok kriterli karar verme yöntemlerinden biri olan VIKOR yöntemi, belirlenen kriterlere göre seçenekler arasından seçim ve sıralama yapılmasına olanak tanır. VIKOR yöntemi (Vise Kriterijumska Optimizacija I Kompromisno Resenje) 1998 yılında Opricovic tarafından geliştirilmiştir. Yöntemin temeli "ideal çözüme yakınlık" ölçümüne dayanmaktadır (Gün ve Kurtuluş, 2018).

Ele alınan probleme ait kriterler ve karar alternatiflerinin belirlenmesinin ardından, bir karar matrisi oluşturulur. Karar matrisinin satırları karar alternatiflerini, sütunları ise kriterleri göstermektedir. Yöntemin uygulanma aşamaları 6 adımdan oluşmaktadır (Kuzu, 2015):

1.Adım: En iyi ve en kötü kriter değerlerinin belirlenmesi

2.Adım: Normalizasyon işlemi ve normalizasyon matrisinin oluşturulmasi

3.Adım: Normalize karar matrisinin ağırlıklandırılması

4.Adım: Si ve Ri değerlerinin hesaplanması

5.Adım: Qi değerlerinin hesaplanması

6.Adım: Alternatiflerin sıralanması ve koşulların denetlenmesi 


\section{Literatür Taramas1}

Sağlık alanında ülke karşılaştırmaları ve sıralamalarını konu alan çalışmalar, kullanılan kriterlere göre sınıflandırılarak Tablo 1'de özetlenmiştir. Literatürde yer alan çalışmaların büyük bir kısmının hastanelere ait göstergeleri kullandığı gözlemlenmektedir. Bunun dışında doktorlar, hemşireler, hastane yatakları ve mezunlar gibi sağlık kaynağı göstergelerine de yapılan sıralama çalışmalarında yer verildiği gözlemlenmiştir. Ebeler, bakım personeli, eczacılar, fizyoterapistler, hastane istihdamı, sağlık çalışanı maaşları, medikal teknolojiler gibi diğer göstergelerin ise çalışmalarda kullanılmadığı görülmüştür. İlgili göstergelere ait tam verilerin yayınlanmamış olmasının, bu eksikliğe sebep olan faktörlerden biri olduğu düşünülmektedir.

Tablo 1. Literatürde yer alan çalışmalarn özeti

\begin{tabular}{|c|c|}
\hline Sınıflandırılmış Göstergeler & Çalışmalar \\
\hline Atık arıtma göstergeleri & $(\mathrm{Lu}$, You, Liu, ve Li, 2016) \\
\hline Hekimler & $\begin{array}{l}\text { (Taş, C., Bedir, N., Eren, T., Alağaş, H.M., Çetin, 2018), (De- } \\
\text { ğirmenci ve Yakıcı Ayan, 2020) }\end{array}$ \\
\hline Hasta bilgileri & $\begin{array}{l}\text { (Değirmenci ve Yakıcı Ayan, 2020), (Alpaykut, 2017), (Pek- } \\
\text { kaya ve Dökmen, 2019), (Shojaei, Karimlou, Mohammadi, ve } \\
\text { Malekafzali, 2016) }\end{array}$ \\
\hline Hastaneler & $\begin{array}{l}\text { (Taş, C., Bedir, N., Eren, T., Alağaş, H.M., Çetin, 2018), (Gü- } \\
\text { dük ve Güdük, 2017), (Avcı, 2018), (Böker ve Çetin, 2020), } \\
\text { (Koçhisarlı ve Özsarı, 2019), (Senvar, Otay, ve Bolturk, 2016), } \\
\text { (Zhang et al., 2020), (Shojaei et al., 2016), (Jafari, Seyedjavadi, } \\
\text { ve Zaboli, 2020), (Mobinizadeh, Raeissi, Nasiripour, Olyaee- } \\
\text { manesh, ve Tabibi, 2016), (Torkzad ve Beheshtinia, 2019) }\end{array}$ \\
\hline Hastane yatakları & $\begin{array}{l}\text { (Değirmenci ve Yakıcı Ayan, 2020), (Güdük ve Güdük, } \\
\text { 2017), (Pekkaya ve Dökmen, 2019) }\end{array}$ \\
\hline Hemşireler & $\begin{array}{l}\text { (Değirmenci ve Yakıcı Ayan, 2020), (Esen, Yiğit, ve Güldan, } \\
\text { 2019) }\end{array}$ \\
\hline İyi yaşam endeksi göstergeleri & (Koçhisarlı ve Özsarı, 2019) \\
\hline Mezunlar & Ayyıldız, E., ve Demirci, E., (2018) \\
\hline Çeşitli sağlık göstergeleri & (Tezcan, 2020) \\
\hline
\end{tabular}

\section{Analiz Sonuçları}

Çalışma kapsamında oluşturulan karar matrisinde karar alternatiflerini OECD ülkeleri oluştururken, kriterleri ise sağlık kaynakları göstergelerinden "1000 kişi başına düşen pratisyen hekim sayısı", "1000 kişi başına düşen uzman hekim sayısı", "1000 kişi başına düşen toplam hastane sayısı, 
bir milyon kişi başına düşen bilgisayarlı tomografi tarayıcı sayısı", "bir milyon kişi başına düşen manyetik rezonans görüntüleme birimi sayısı", "bir milyon kişi başına düşen pozitron emisyon tomografisi (PET) tarayıcı sayısı", "bir milyon kişi başına düşen mamograf sayısı" ve "bir milyon kişi başına düşen radyasyon tedavi ekipmanı sayısı" değişkenleri oluşturmaktadır. Her bir ülkenin, sağlık kaynağı göstergelerine ait 2019 yılı değerleri kullanılarak karar matrisi elde edilmiştir. TOPSIS ve VIKOR yöntemlerinin uygulanmasında aynı karar matrisi kullanılmıştır. Her iki yöntemin uygulanmasında da belirlenen sekiz adet kriterin ağırlıkları eşit olarak kabul edilmiştir.

TOPSIS yönteminin uygulanması sonucunda ideal ve ideal olmayan noktalara olan uzaklık değerleri hesaplanmıştır. Elde edilen bu değerler, $C_{i}^{*}=\frac{S_{i}^{-}}{S_{i}^{-}+S_{i}^{*}}$ formülünde yerine konularak, ideal çözüme göreli yakınlık değerleri hesaplanmıştır ve tüm bu değerler Tablo 2'de gösterilmiştir. Elde edilen $\mathrm{Ci}^{*}$ değerlerine göre yapılan sıralama sonucunda, en yüksek ideal çözüme göreli yakınlık değerine sahip olan ülke, belirlenen kriterler açısından en iyi durumda olan ülke olarak belirlenmiştir. TOPSIS analizi sonucunda, OECD ülkelerinin sıralamaları Tablo 3 'te gösterilmektedir.

Tablo 2. TOPSIS yöntemi ile ideal çözüme göreli yakınlıklar tablosu

\begin{tabular}{|c|c|c|c|}
\hline Ülkeler & $\begin{array}{l}\mathrm{Si}^{*} \\
\text { İdeal Uzaklıklar }\end{array}$ & $\begin{array}{l}\text { Si- } \\
\text { Negatif İdeal } \\
\text { Uzaklıklar }\end{array}$ & $\begin{array}{l}\mathrm{Ci}^{*} \\
\text { İdeal Çözüme Göreli Yakınlık }\end{array}$ \\
\hline Avustralya & 0,0865 & 0,0771 & 0,4714 \\
\hline Avusturya & 0,0872 & 0,0633 & 0,4208 \\
\hline Kanada & 0,1202 & 0,0300 & 0,1999 \\
\hline Şili & 0,1240 & 0,0313 & 0,2014 \\
\hline Çekya & 0,1116 & 0,0439 & 0,2822 \\
\hline Danimarka & 0,0939 & 0,0860 & 0,4779 \\
\hline Estonya & 0,1107 & 0,0380 & 0,2557 \\
\hline Finlandiya & 0,0973 & 0,0578 & 0,3724 \\
\hline Yunanistan & 0,0947 & 0,0818 & 0,4636 \\
\hline Macaristan & 0,1201 & 0,0368 & 0,2346 \\
\hline İzlanda & 0,1016 & 0,0553 & 0,3527 \\
\hline İrlanda & 0,1075 & 0,0512 & 0,3229 \\
\hline İtalya & 0,0885 & 0,0638 & 0,4189 \\
\hline Güney Kore & 0,0756 & 0,0940 & 0,5540 \\
\hline Letonya & 0,1057 & 0,0461 & 0,3037 \\
\hline Litvanya & 0,1077 & 0,0488 & 0,3120 \\
\hline Lüksemburg & 0,1143 & 0,0365 & 0,2420 \\
\hline Meksika & 0,1406 & 0,0127 & 0,0828 \\
\hline Yeni Zelanda & 0,1137 & 0,0438 & 0,2782 \\
\hline Polonya & 0,1218 & 0,0339 & 0,2177 \\
\hline
\end{tabular}




\begin{tabular}{llll} 
Portekiz & 0,1056 & 0,0644 & 0,3788 \\
Slovenya & 0,1155 & 0,0327 & 0,2204 \\
İspanya & 0,1133 & 0,0348 & 0,2350 \\
Türkiye & 0,1258 & 0,0221 & 0,1495 \\
Birleşik Krallık & 0,1292 & 0,0253 & 0,1638 \\
ABD & 0,0829 & 0,0932 & 0,5293 \\
\hline
\end{tabular}

Tablo 3. TOPSIS yöntemi sonucunda elde edilen OECD ülkeleri sıralamalar

\begin{tabular}{ll}
\hline Ülkeler & $\mathbf{C i}^{*}$ \\
\hline Güney Kore & 0,5540 \\
ABD & 0,5293 \\
Danimarka & 0,4779 \\
Avustralya & 0,4714 \\
Yunanistan & 0,4636 \\
Avusturya & 0,4208 \\
İtalya & 0,4189 \\
Portekiz & 0,3788 \\
Finlandiya & 0,3724 \\
İzlanda & 0,3527 \\
İlanda & 0,3229 \\
Litvanya & 0,3120 \\
Letonya & 0,3037 \\
Çekya & 0,2822 \\
Yeni Zelanda & 0,2782 \\
Estonya & 0,2557 \\
Lüksemburg & 0,2420 \\
İspanya & 0,2350 \\
Macaristan & 0,2346 \\
Slovenya & 0,2204 \\
Polonya & 0,2177 \\
Şili & 0,2014 \\
Kanada & 0,1999 \\
Birleşik Krallı & 0,1638 \\
Meksika & 0,1495 \\
\hline
\end{tabular}

VIKOR analizinde ağırlıklandırılmış normalize karar matrisinin oluşturulmasının ardından, her bir alternatif için ortalama ve en kötü grup skorlarını gösteren $\mathrm{Si}$ ve Ri değerleri hesaplanır. Elde edilen bu değerler ve $Q_{i}=\frac{q *\left(S_{i}-S^{*}\right)}{S^{-}-S^{*}}+\frac{(1-q) *\left(R_{i}-R^{*}\right)}{R^{-}-R^{*}}$ formülü kullanılarak ülkelerin siralamalarını yapabilmek için ihtiyaç duyulan Qi değerleri elde edilir. Bu değerin hesaplanmasında kullanılan q parametresi maksimum grup faydasını (kriterlerin çoğunluğunun ağırlığını) ifade etmektedir. VIKOR yönteminde, $\mathrm{q}=\{0,00 ; 0,25 ; 0,50 ; 0,75 ; 1,00\}$ değerleri kullanılarak Qi değerleri beş farklı şekilde hesaplanabilmektedir. Ardından sıralamaların doğru- 
luğu kontrol edilmelidir. Bu amaçla, kabul edilebilir avantaj ve kabul edilebilir istikrar koşulları sınanmaktadır. Tüm bu işlemler sonucunda VIKOR analizi ile elde edilen, OECD ülkelerinin sıralamaları Tablo 4'te gösterilmektedir.

Tablo 4. VIKOR yöntemi ile elde edilen OECD ülkeleri sıralaması

\begin{tabular}{|c|c|c|c|c|}
\hline Ülkeler & $\mathrm{Si}$ & $\mathbf{R i}$ & Qi & Siralama \\
\hline Avustralya & 0,5206 & 0,1064 & 0,1700 & 4 \\
\hline Avusturya & 0,5920 & 0,0989 & 0,3050 & 7 \\
\hline Kanada & 0,8316 & 0,1183 & 0,7573 & 23 \\
\hline Şili & 0,8467 & 0,1250 & 0,7858 & 24 \\
\hline Çekya & 0,7138 & 0,1218 & 0,5349 & 15 \\
\hline Danimarka & 0,5629 & 0,1102 & 0,2498 & 5 \\
\hline Estonya & 0,7505 & 0,1231 & 0,6043 & 17 \\
\hline Finlandiya & 0,6091 & 0,1034 & 0,3371 & 8 \\
\hline Yunanistan & 0,4689 & 0,1192 & 0,0723 & 3 \\
\hline Macaristan & 0,7973 & 0,1179 & 0,6925 & 20 \\
\hline İzlanda & 0,6470 & 0,1088 & 0,4087 & 10 \\
\hline İrlanda & 0,6754 & 0,1192 & 0,4623 & 12 \\
\hline İtalya & 0,5681 & 0,1014 & 0,2597 & 6 \\
\hline Güney Kore & 0,4574 & 0,1093 & 0,0507 & 2 \\
\hline Letonya & 0,6885 & 0,1119 & 0,4871 & 13 \\
\hline Litvanya & 0,6600 & 0,1172 & 0,4333 & 11 \\
\hline Lüksemburg & 0,7487 & 0,1210 & 0,6008 & 16 \\
\hline Meksika & 0,9601 & 0,1250 & 1,0000 & 26 \\
\hline Yeni Zelanda & 0,6997 & 0,1120 & 0,5082 & 14 \\
\hline Polonya & 0,8151 & 0,1244 & 0,7261 & 21 \\
\hline Portekiz & 0,6297 & 0,1195 & 0,3761 & 9 \\
\hline Slovenya & 0,7679 & 0,1113 & 0,6370 & 19 \\
\hline İspanya & 0,7594 & 0,1105 & 0,6210 & 18 \\
\hline Türkiye & 0,8821 & 0,1240 & 0,8526 & 25 \\
\hline Birleşik Krallık & 0,8312 & 0,1243 & 0,7565 & 22 \\
\hline $\mathrm{ABD}$ & 0,4306 & 0,1250 & 0,0000 & 1 \\
\hline
\end{tabular}

TOPSIS ve VIKOR yöntemlerinin uygulanması sonucunda elde edilen ülke sıralamaları Tablo 5'te karşılaştırmalı olarak yer almaktadır. Sonuçlar karşılaştırıldığında her iki yöntemde de benzer sıralamaların elde edildiği göze çarpmaktadır.

Tablo 5. TOPSIS ve VIKOR yöntemleri ile elde edilen sıralamaların karşılaştırmah tablosu

\begin{tabular}{lll}
\hline S1ralama & TOPSIS & VIKOR \\
\hline 1 & Güney Kore & ABD \\
2 & ABD & Güney Kore \\
3 & Danimarka & Yunanistan \\
4 & Avustralya & Avustralya \\
5 & Yunanistan & Danimarka
\end{tabular}




\begin{tabular}{lll}
6 & Avusturya & İtalya \\
7 & İtalya & Avusturya \\
8 & Portekiz & Finlandiya \\
9 & Finlandiya & Portekiz \\
10 & İzlanda & İzlanda \\
11 & İrlanda & Litvanya \\
12 & Litvanya & İrlanda \\
13 & Letonya & Letonya \\
14 & Çekya & Yeni Zelanda \\
15 & Yeni Zelanda & Çekya \\
16 & Estonya & Lüksemburg \\
17 & Lüksemburg & Estonya \\
18 & İspanya & İspanya \\
19 & Macaristan & Slovenya \\
20 & Slovenya & Macaristan \\
21 & Polonya & Polonya \\
22 & Şili & Birleşik Krallı \\
23 & Kanada & Kanada \\
24 & Birleşik Krallık & Şili \\
25 & Türkiye & Türkiye \\
26 & Meksika & Meksika \\
\hline
\end{tabular}

\section{Tartışma ve Sonuç}

TOPSIS ve VIKOR yöntemlerinin uygulanması sonucunda yapılan sıralamada üst sırada yer alan ülkelerin $A B D$ ve Güney Kore olduğu göze çarpmaktadır. İki yöntem ile elde edilen sıralamalar tamamen aynı olmamakla birlikte, oldukça benzer sonuçlar sergilemektedirler. Sahip olunan sağlık kaynakları açısından son sırada yer alan ülke her iki analiz için de Meksika olmuştur. Türkiye ise 26 OECD ülkesi arasında 25. sırada yer almaktadır.

Bin kişi başına düşen pratisyen hekim ve uzman hekim sayıları kriterleri açısından Türkiye'nin diğer OECD ülkelerine yakın bir değere sahip olduğu görülmektedir. Ancak medikal teknoloji kapsamında değerlendirilen diğer beş kriter açısından incelendiğinde Türkiye'nin az sayıda tarayıcı ve ekipmana sahip olduğu gözlemlenmektedir. Bu doğrultuda da TOPSIS ve VIKOR analizleri sonucunda Türkiye'nin 25. sirada yer aldığ 1 görülmektedir.

Gelişmiş ve zengin ülke sağlık kaynağ1 seviyelerine erişebilmede Türkiye'nin ilave kaynaklara ihtiyacı olduğu yapılan sıralamaklar sonucunda göze çarpmaktadır. Çalışmada ele alınan kaynaklar açısından değerlendi- 
rildiğinde, bu kaynakların medikal teknolojiler kapsamında değerlendirilecek olan tomografi tarayıcılar, manyetik rezonans görüntüleme birimleri, PET tarayıcıları, mamograflar ve radyasyon tedavi ekipmanları olduğu sonucuna varılmaktadır.

Elbette bir ülkenin sağlık kaynakları açısından iyi bir noktada olması, bu ülkenin sağlık sisteminin ve bu sistemin etkinliğinin yüksek olduğu anlamına gelmemektedir. Bu noktada ülkelerin sahip oldukları sağlık kaynaklarını ne denli etkin kullandıkları da önem taşımaktadır ve bu konuda ayrıca analizler yapılması gerekmektedir. Ülkelerin sağlık kaynaklarını artırmalarının yanı sıra bu kaynakları daha etkin ve daha verimli kullanarak, sağlık statülerinin iyileştirmeleri önem taşımaktadır.

Bu çalışma kapsamında değerlendirilemeyen diğer sağlık kaynağı göstergelerine ait verilerin elde edilmesi ile daha geniş kapsamlı bir sıralama ve karşılaştırma yapabilmenin mümkün olduğu düşünülmektedir. İncelenen kriterlerin uzman görüşleri alınarak ve farklı karar verme teknikleri kullanılarak ağırlıklandırılması sonrasında, TOPSIS ve VIKOR tekniklerinin uygulanarak ülkelerin sıralamalarının gözlemlenmesi gelecek araştırmacilara önerilmektedir. 


\title{
EXTENDED ABSTRACT \\ Comparison of OECD Countries in Terms of Health Resource Indicators Using TOPSIS and VIKOR Methods
}

\author{
* \\ Yeter Demir Uslu \\ Istanbul Medipol University
}

\section{Introduction}

To increase the quality of health services, it is important to deliver the services to those who need them at the right time. Therefore, the system needs to be updated every day in line with the conditions of that day. In general, health systems identify resources for health care delivery and provide the management, organization, and allocation of resources.

Resource management can be seen as the analytical or strategic starting point of all functions of the management phenomenon, including budget and planning. It ensures the effective use of all resources necessary to achieve corporate goals. For healthcare institutions, having a resource management plan is an effective tool for optimizing human resources, materials, and budget efficiency. In institutional processes, the discovery of inadequate or inefficient resources and their inclusion in business processes by their purpose serve the understanding of quality in health.

\section{The Relationship Between Resource Utilization and Health Service Outcomes}

To ensure the manageability of public health services, it is necessary to carry out consumption, supply, and technology management processes and to manage the relationship between them. Decision-making processes are very important to ensure the sustainability of the relationship established in the management process.

Resource management in health can be defined as a process designed to activate strategic planning, financial management, budgeting, manage- 
ment accounting, customer relations management, human resources management, and auditing studies in health facilities to ensure the effective and efficient use of resources in the health system.

Regarding health resources in Turkey, the first things that come to the mind are human resources and financial resources. Undoubtedly, human resource management and financial resources management are among the basic elements in health institutions. However, in addition to human resources and financial resources, it should not be forgotten that the materials used in service delivery and related effective material management, as well as health resources, which are based on information and communication technologies infrastructure, are also important components.

Classification of sources of health in the national and international literature include:

1. Staff (Medical, nursing, clinical and administrative support)

2. Materials (Medical and other)

3. Building Equipment (Information and Communication Technologies)

4. Monetary Resources, (Yüksel, 2012).

Interdependence and division of labor should be high in the provision of health services, and a fair, effective and efficient process should be carried out without sacrificing quality. In addition, it is necessary to manage the materials used in health services, to store the consumable's inappropriate conditions after the procurement activities, to determine the distribution channels, and to ensure the realization and use of fast and timely delivery. Since the construction of the buildings used in the provision of health services, care is taken to make the use of modern technologies widelly in all designs and processes, to organize all clinical and non-clinical workflows, and to be process-oriented and ergonomic. Thanks to the technological developments and digital transformation in the health sector, hospitals have also evolved into digital hospitals with more technological equipment. This situation increases the potential to manage health care processes more quickly and effectively and to deliver services to patients who require priority and specific care more quickly.

With the Health Transformation Program initiated in Turkey in 2003, the health system has been transformed and redesigned and health reforms have been carried out. In this process, by establishing General 
Health Insurance, a roof organization was established that aims to cover all citizens of the country. Looking at developing countries and Turkey; success is observed in health indicators and health expenditure budgets at a noticeably higher rate than the average. Looking at the population of Turkey, it is predicted that with the increase in the elderly population in recent years, the burden of chronic diseases will increase in the future and the share allocated to health expenditures will increase accordingly. Considering factors such as the change in the burden of disease, the increase in the elderly population, the prolongation of the length of stay, and the changes in health technologies, the need for process designs is revealed to be reworked in the organization, management, and financing methods of the health system.

\section{Health Resources}

Total health and social employment; doctors, midwives, nurses, care personnel, dentists, pharmacists, physiotherapists, hospital employment, graduates, salaries of health workers, hospitals, hospital beds, and medical technology are evaluated within the framework of this criteria. By evaluating the titles one by one, a total of 124 health resource indicators were determined by the OECD (OECD, 2021).

The criteria covered in the study;

The number of computerized tomography scanners per million people, the number of Magnetic Resonance Imaging (MRI) units, the number of Positron Emission Tomography (PET) scanners, the number of Mammographies, the number of Radiation Therapy devices includes health resources evaluated in the medical technology class. We can list other variables per 1000 people (number of general practitioners, number of specialist physicians, total number of hospitals). These variables are evaluated in the OECD classification of doctors and hospital beds. OECD countries with missing data and health resource indicators were not included in the study. Therefore, in this study, 26 OECD countries are ranked according to 8 health resource indicators. Unlike studies based on country comparisons made in the past, medical technology indicators which have an important place among health resources, are included in this study. 


\section{Method}

The method of the study was designed concerning some studies that used TOPSIS and VIKOR, which are multi-criteria decision-making methods, in the literature (Yllmaz ve Yakut, 2021). In this framework, the ranking of the countries in terms of health resource indicators determined by using the TOPSIS and VIKOR methods, which are multi-criteria decision-making methods, was carried out in the study, and finally, the results obtained by the two methods were compared. It was assumed that the criteria covered in the study were of equal importance and TOPSIS and VIKOR analyzes were applied under this assumption.

TOPSIS method, which is one of the multi-criteria decision-making methods, allows making the best choice among the decision alternatives and ranking these alternatives, taking the determined criteria into account (Özüdoğru ve Görener, 2018). TOPSIS (Technique for Order Preference by Similarity to Ideal Solution) was developed by Hwang and Yoon in 1981. The VIKOR method (Vise Kriterijumska Optimizacija I Kompromisno Resenje), which is one of the multi-criteria decision-making methods, allows selection and ranking among the options according to the determined criteria andwas developed by Opricovic in 1998. The basis of the method is based on the measurement of "closeness to the ideal solution" (Gün ve Kurtuluş, 2018).

\section{Literature Review}

Studies on country comparisons and rankings in the field of health are classified according to the criteria used. It is observed that most of the studies in the literature use indicators belonging to hospitals. Apart from this, it has been observed that ranking studies with health resource indicators such as doctors, nurses, hospital beds, and graduates are also included. It was observed that other indicators such as midwives, care personnel, pharmacists, physiotherapists, hospital employment, health worker salaries, medical technologies were not used in the studies. It is thought that the fact that the full data of the relevant indicators has not been published is one of the factors causing this deficiency. 


\section{Analysis Results}

In the decision matrix created within the scope of the study, the decision alternatives are formed by OECD countries. The criteria in the decision matrix created within the scope of the study are the variables that are one of the health resources indicators. These variables are; "Number of general practitioners per 1000 people", "Number of specialist physicians per 1000 people", "Total number of hospitals per 1000 people", "Number of computerized tomography scanners per one million people", "Magnetic resonance imaging per million people" "number of imaging units", "number of positron emission tomography (PET) scanners per million inhabitants", "mammograms per million inhabitants", and "radiation therapy equipment per million inhabitants". The decision matrix was obtained by using the 2019 values of the health resource indicators of each country. The same decision matrix was used in the application of TOPSIS and VIKOR methods.

In the ranking of OECD countries obtained as a result of the TOPSIS method, South Korea ranks first, the USA ranks second, and Denmark ranks third. Turkey is in the 25th place.

When we look at the rankings of OECD countries obtained by VIKOR analysis, Australia ranks second, Canada ranks third, and Turkey ranks 24th.

The country rankings obtained as a result of the application of TOPSIS and VIKOR methods were compared. When the results are compared, it is striking that similar rankings were obtained in both methods. As a result of the TOPSIS method, the ranking was listed as South Korea, USA, Denmark, while in the VIKOR method, the ranking was listed as USA, South Korea, and Greece . It is seen that Turkey ranks 25 th in both method rankings.

\section{Discussion and Conclusion}

The top-ranking countries in the rankings resulting from the application of TOPSIS and VIKOR methods are the USA and South Korea. In both analyses, Mexico was the last country in terms of health resources. Turkey, on the other hand, ranks 25th among 26 OECD countries. 
It is seen that Turkey has a value close to other OECD countries in terms of the number of general practitioners and specialist physicians per thousand people. However, when examined in terms of the other five criteria evaluated within the scope of medical technology, it is observed that Turkey has few scanners and equipment.

As a result of the rankings, it is striking that Turkey needs additional resources in order to reach the health resource levels of developed and rich countries.

Making more comprehensive ranking and comparisons could be possible by obtaining data from other health resource indicators that cannot be evaluated within the scope of this study. It is recommended to future researchers to observe the rankings of countries by applying TOPSIS and VIKOR techniques, after weighting the examined criteria by taking expert opinions and using different decision-making techniques.

\section{Kaynakça / References}

Acar, E. (2015). Kamu kesiminde karar vermede stratejik planlamanın rolü ve önemi. F. Kırışık ve Ö. Önder (Der.), Kamu Yönetimi ve Siyaset Biliminde Karar Verme içinde (s.511-529) . Ankara: Detay Yayıncılık.

Alpaykut, S. (2017). Türkiye' de illerin yaşam memnuniyetinin temel bileşkenler analizi ve TOPSIS Yöntemiyle ölçümü üzerine bir inceleme. Süleyman Demirel Üniversitesi Sosyal Bilimler Enstitüsü Dergisi, 4(29), 367395.

Arıkboğa, Ü. (2015). Belediye bütçelerinde karar verme süreci. F. Kırışık ve Ö. Önder (Der.), Катu Yönetimi ve Siyaset Biliminde Karar Verme içinde (s.145-170) . Ankara: Detay Yayıncilik.

Avaner, T. ve Avaner, E. (2018). Gazi Üniversitesi İktisadi ve İdari Bilimler Fakültesi Dergisi Sağlik hizmetlerinde etkin kaynak yönetimi : Vitreoretinal Cerrahi ve Total Parenteral Nutrisyon ( TPN ) Cihaz ve malzemelerinin merkezi alım örnekleri üzerinden bir değerlendirme. Gazi Üniversitesi İktisadi ve İdari Bilimler Fakültesi Dergisi, 1, 131-152.

Avcl, K. (2018). Ankara İl merkezindeki bir eğitim ve araştırma hastanesinin finansal performansının topsıs yöntemi ile değerlendirilmesi. Iş̧letme Bilimi Dergisi, 6(2), 25-44.

Ayyıldız, E. ve Demirci, E. (2018). Türkiye'de yer alan şehirlerin yaşam kalitelerinin SWARA Entegreli TOPSIS Yöntemi ile belirlenmesi. Pamukkale Üniversitesi Sosyal Bilimler Enstitüsü Dergisi ,2018(30), 67-87. 
Bekmezci, M. (2018). Sağllk kurumlarında tedarik ve malzeme yönetimi. II. International Applied Social Sciences Congress, 714-717.

Böker, Z. ve Çetin, O. (2020). Sağllk Sektöründe Abc-Ved Ahp ve Topsıs Yöntemleri Kullanılarak Çok Kriterli Stok Sinıflandırması. Marmara Üniversitesi Öneri Dergisi, 15(53), 178-208.

Burns, L.R., DeGraaff, R.A., Danzon, P.M., Kimberly, J.R., Kissick, W.L., ve Pauly, M.V. (2002). The Wharton School study of the health care value chain. The health care value chain: producers, purchasers and providers. San Francisco: Jossey-Bass, 3-26.

Culyer, A. J., ve Newhouse, J. P. (2000). Introduction: The state and scope of health economics. In Handbook of Health Economics, 1, 1-8.

Değirmenci, N., ve Yakıcı Ayan, T. (2020). OECD Ülkerïnï sağlık göstergelerï açısından bulanık kümeleme analïzï ve topsis yöntemïne göre değerlendirilmesi. Hacettepe Üniversitesi İktisadi ve İdari Bilimler Fakültesi Dergisi, 38(2), 229-241.

Ecevit, E. ve Çetin, M. (2010). Sağlık Harcamalarının ekonomik büyüme üzerindeki etkisi: OECD Ülkeleri üzerine bir panel regresyon analizi. Doğuş Üniversitesi Dergisi, 2(11), 166-182.

Esen, H., Yiğit, V. ve Güldan, S. (2019). Hastanelerde AHP ve TOPSIS Yöntemi ile personel seçimi. Avrasya Sosyal ve Ekonomi Araştırmaları Dergisi (ASEAD), 6(12), 112-128.

Güdük, Ö. ve Güdük, Ö. (2017). Palyatif bakım ünitelerï performansınınTopsïs Yöntemï ile değerlendirilmesi. Adıyaman Üniversitesi Să̆lık Bilimleri Dergisi, 3(2), 511-520.

Gulhan, Y. ve Coskun, S. (2017). TS EN 15224 healthcare service - the comparison of quality management system to other quality systems in healthcare. Pressacademia, 4(3), 410-416.

Gün, İ. ve Kurtuluş, S. A. (2018). Sağllk göstergeleri açısından Türkiye'de Bölgeler arası eşitsizlikler. E. Önder ve B. F. Yıldırım (Der.), Sağlık Yönetiminde Karar Verme - I, içinde (s.401-426). Bursa: Dora Yayınları.

Hayaloğlu, P. ve Bal, H. Ç. (2015). Üst orta gelirli ülkelerde sağlık harcamaları ve ekonomik büyüme ilişkisi. İşletme ve İktisat Çalışmaları Dergisi, 3(2), $35-44$.

Jafari, M., Seyedjavadi, M. ve Zaboli, R. (2020). Assessment of performance in teaching hospitals: Using multicriteria decision-making techniques. Journal of Education and Health Promotion, 9(1), 1-5. 
Koçhisarlı, S. ve Özsarı, Ç. (2019). İyi yaşam endeksi göstergeleri dikkate alınarak İskandinav Ülkelerinin TOPSIS Yöntemi ile değerlendirilmesi. Akademik Sosyal Araştırmalar Dergisi, 7(94), 466-480.

Kuzu, S. (2015). VIKOR. In B. F. Yıldırım ve E. Önder (Eds.), Çok Kriterli Karar Verme Yöntemleri (2.Baskı, p.117-132). Bursa: Dora Yayınları.

Lu, C., You, J. X., Liu, H. C. ve Li, P. (2016). Health-carewaste treatment technology selection using the interval 2-Tuple induced TOPSIS method. International Journal of Environmental Research and Public Health, 13(6), 562-578.

Lustig, N. (2007). Investing in Health for Economic Development: The Case of Mexico. In Advancing Development, Palgrave Macmillan, London, 168182.

Mobinizadeh, M., Raeissi, P., Nasiripour, A. A., Olyaeemanesh, A. ve Tabibi, S. J. (2016). A model for priority setting of health technology assessment: The experience of AHP-TOPSIS combination approach. DARU, Journal of Pharmaceutical Sciences, 24(1), 1-12.

Özcan, Y. (2013). Sağlık kurumları yönetiminde sayısal yöntemler. (Ş. Kavuncubaşı ve S. Yıldırım, Çev.), Ankara: Siyasal Kitabevi.

Özdemir, M. (2015). TOPSIS. In B. F. Yıldırım ve E. Önder (Der.), Çok Kriterli Karar Verme Yöntemleri içinde (2.Bask1, s.133-153). Bursa: Dora Yayınları.

Özüdoğru, A. G. ve Görener, A. (2018). Hastane yeri seçiminde çok kriterli karar verme yöntemlerinin kullanımı. E. Önder ve B. F. Yıldırım (Der.), Să̆lık Yönetiminde Karar Verme - I içinde (1.Baskı, s.63-84). Bursa: Dora Yayınları.

Pekkaya, B. ve Dökmen, G. (2019). OECD Ülkeleri kamu sağlık harcamalarınin çok kriterli karar verme yöntemlerï ile performans değerlendïrmesï. Uluslararası Yönetim İktisat ve Işletme Dergisi, 15(4), 923951.

Senvar, O., Otay, I. ve Bolturk, E. (2016). Hospital Site Selection via Hesitant Fuzzy TOPSIS. IFAC-PapersOnLine, 49(12), 1140-1145.

Shojaei, P., Karimlou, M., Mohammadi, F. ve Malekafzali, H. (2016). Health Impact Assessment of Urban Development Project. Global Journal of Health Science, 8(9), 224.

T.C. Kalkınma Bakanlığı. (2014). 2014-2018 Sağlık Hizmetlerinin Etkinliğinin Artırılması ve Mali Sürdürülebilirlik. Özel İhtisas Komisyonu Raporu, Onuncu Kalkınma Planı. 
Taş, C., Bedir, N., Eren, T., Alağaş, H.M. ve Çetin, S. (2018). AHP-TOPSIS Yöntemleri Entegrasyonu ile poliklinikleri değerlendirilmesi: Ankara'da bir uygulama. Sağllk Yönetimi Dergisi, 2(1), 1-17.

Tengilimoğlu, D. ve Yiğit, V. (2013). Sağglı işletmelerinde tedarik zinciri ve malzeme yönetimi. Ankara: Nobel Yayın Dağıtım.

Tezcan, N. (2020). Sürdürülebilir kalkınma amaçları kapsamında Türkiye'de sağlık göstergelerinin analizi. İstanbul Ticaret Üniversitesi Sosyal Bilimler Dergisi, 202, 202-217.

Torkzad, A. ve Beheshtinia, M. A. (2019). Evaluating and prioritizing hospital service quality. International Journal of Health Care Quality Assurance, 32(2), 332-346.

Türkiye İstatistik Kurumu. (2012). Türkiye'nin demografik yapısı ve geleceği. 2010-2050. (01.03.2021) tarihinde https://tuikweb.tuik.gov.tr/PreHaberBultenleri.do? $i d=13140$ adresinden erişildi.

Türkiye Sağlık Turizmi Derneği. (n.d.). Sağlıkta dönüşüm - sağlıkta dönüşüm programı ve uygulama sonuçları. (15.03.2021) tarihinde http://www.saglikturizmi.org.tr/tr/st-donusum/program adresinden erişildi.

Tutuncu, O. ve Kucukusta, D. (2008). The role of supply chain management integration in quality management system for hospitals. International Journal of Management Perspectives, 1(1), 31-39.

Yılmaz, Ö. ve Yakut, E. (2021). Entropi temelli TOPSIS ve VIKOR Yöntemleri ile Bankacıllk sektöründe finansal performans değerlendirmesi. Atatürk Üniversitesi İktisadi ve İdari Bilimler Dergisi, 35(4), 1297-1321.

Yüksel, H. (2012). Yalın sağlık. Ankara: Nobel Yayınevi.

Zhang, C., Li, R., Xia, Y., Yuan, Y., Dinçer, H. ve Yüksel, S. (2020). Analysis of environmental activities for developing public health investments and policies: A comparative study with structure equation and interval type 2 fuzzy hybrid models. International Journal of Environmental Research and Public Health, 17(6), 1977.

\section{Kaynakça Bilgisi / Citation Information}

Demir Uslu, Y. (2021). TOPSIS ve VIKOR Yöntemleri kullanılarak OECD Ülkelerinin sağlık kaynağı göstergeleri açısından karşılaştırılması. OPUS-Uluslararası Toplum Araştırmaları Dergisi, 18(44), 7668-7692. DOI: 10.26466/opus. 961183. 